\title{
Editorial
}

\section{Foreign Policy: A Human Systems View}

Human Systems Management is concerned with global competition; knowledge-based corporate strategies and economic transformations rarely cross the narrower boundaries of business and management areas. Consequently, disproportionately large areas of human interaction remain virtually unaffected by the advances in total quality management, customer integration, employee empowerment, systems optimization, zero-level hierarchies and knowledge-information revolution.

While businesses and economies are becoming globally competitive, political systems and political strategies of most powerful nations are being run by career politicians, aged old-school diplomats and journalists-cum-strategists.

Questions of quality, responsibility, accountability, competence and performance rarely enter into traditional foreign policy deliberations. No systems optimization, no quality management, no learning and no long-term grounding appear to be of importance. Day-to-day maneuvering, propaganda, trouble-shooting and personality fetishism appear to prevail. Yet, foreign policy of the last remaining superpower does affect human systems everywhere and in a most significant way.

This traditional distinction between foreign and domestic policy, as in the case of corporate national and global strategy, is rapidly losing its meaning and efficacy in the global world. It is not, as U.S. government keeps insisting, that 'Good foreign policy is a good domestic policy', but the other way around: Good domestic policy is the best foreign policy. Similarly, U.S. domestic purpose cannot be the destructive 'Out of one, many' (U.S. Vice President's speech), but its very opposite, the integrative 'Out of many, one', ex pluribus unum.

The purpose of active, positive foreign policy must be the creation of reliably, friendly, cooperative and cooperating nations or states beyond U.S. borders. This purpose can no longer be served by

\section{IOS Press}

Human Systems Management 13 (1994) 1-4 sharply separating 'foreign' from 'domestic' policy. More than ever before, any discrepancy between what is preferred domestically and recommended externally, promised and delivered, declared and acted upon, etc., is immediately detected anywhere in the world. The gap between (symbolic) description of action and action itself is not as accepted or tolerated as before 1989. Global information is what it says it is: global information. Very little margin for error, promises, deceit, maneuver or symbolic gestures remains.

Many business corporations have successfully (often inevitably) transformed from national, through multinational, to global enterprises. Only national corporations have to rely on a separate 'foreign policy' (foreign or export strategy) in the traditional sense. Multinationals already have many 'foreign policies', trying to match a variety of finished products with a multitude of foreign or domestic users. Global corporations cannot and do not have to distinguish between their foreign and domestic policies: they provide generic, globally desired and acceptable basic products or services, to be completed or finalized locally, according to local preferences, demand and contextual circumstances. The slogan 'Think globally, act locally' finally ceased being a cliché.

While we are entering the era of a global corporation, the U.S. foreign policy has obviously not moved beyond its first, i.e., 'national' stage. It still hovers somewhere in between, in transition. Politics is thus continually being forced out of phase with economics and business. Any modern U.S. foreign policy must correspond to, reflect and take advantage of the global era.

The above used analogy is not superficial. Consider:

National: producing uniform products or services for domestic markets and using a separate export strategy and international marketing to identify and expand foreign markets for such products. 
Multinational: producing differentiated products and services fitted for different foreign and domestic markets by creating a variety of 'foreign' strategies, each one specifically customized to a given circumstance.

Global: producing basic (globally useful), but still incomplete and unfinished products and services which are to be completed and finished by each different market or individual according to specific local wishes and preferences.

It is not difficult to see that foreign policy is not all that different from corporate strategy. In fact, many corporate strategies could serve as useful examples for great foreign policies. But, of course, many should not: business strategy is often in as much of flux and searching as foreign policy. But the trends appear to be more clearly defined and better understood in global business and trade.

Recent U.S. foreign policy has frequently become dissipated (or simply failed) under the conditions of post-cold-war interaction, fuzzily defined or unfocused 'enemy' conceptualization and the large multiplicity of 'issues'.

Yet, if properly understood and conceived, U.S. foreign policy could become the best, most reliable and most effective in the world. The U.S. possesses special competitive advantages and resources, so far ignored or only poorly tapped, which could make its foreign policy unique and focused.

In a global economy, global politics is not and cannot be too far behind. The very notion of foreign policy, as the notion of corporate strategy, changes its meaning and impact in the new framework. Improving and fine-tuning the old notions will not be adequate.

If U.S. foreign policy does not wish to follow the drunken missteps of assorted IBMs and GMs, i.e., their inability to change and adapt to a radically new and different world, then it too has to be structurally reinvented.

The world and especially the U.S. are undergoing unprecedented revolutions in globalization, computers, information economy, management and culture. Consumer, customer, employee, voter and citizen are becoming sovereign actors - their preferences, wishes and strivings are becoming driving forces of institutions. Individuals are starting to reign supreme and direct democracy is becoming their major institution of self-realization.
The U.S. democratic values, principles and experiences have become the only stable focus, the only reliable anchor in the era of perceived turmoil. Although they cannot (and should not) be copied, exported or imposed in all their details, they do represent a much needed point of reference for millions of seekers. Upholding this point of reference brings hope, direction and ultimate sense of purpose to us as well as to the others. Diluting and weakening this point of reference weakens us and the others. Foreign policy must be rooted in these values and principles. It cannot rest on expediency, short-term personification and endless angling for the 'lesser evil'.

In this sense, the U.S. foreign policy has, in recent years, clearly failed or erred on the side of individual accommodation, blurring the vital dimensions of the point of reference. We have erred on the side of:

1. Personification. No individual, no political leader, anywhere, is or could serve as a surrogate or fetish for fundamental principles. No individual could become a reference point in himself. Americans intuitively understand that institutions, not individuals, are the core and anchors of their freedoms and democracy. Yet, in terms of foreign policy, we have allowed the simplifying personification of democracy to muddle our worldview.

2. Democratic process. Democratic process itself has to continually correct its own outcomes. Being democratically elected does not guarantee democratic behavior, values and principles of the elected leader. We must support individuals not because they were democratically elected, but because they respect and uphold democratic process.

3. Media labeling. Labels assigned to parties and individuals by the media should never become a part of foreign policy. We have been exposed to a veritable avalanche of assorted strongmen, thugs, die-hards, criminals, clowns, socialists, warlords, and so on, only to 'eat our own words' later - and they were not even our words. Such labels represent unjustified simplifications of world affairs, suitable for NYT pundits or stand-up comics, but otherwise unworthy and incompatible with intelligent foreign policy.

4. Respect for the voter. Each and any elected person has been brought forth by voters who hold and manifest legitimate reasons, hopes and understandings. Voters did not elect a 'thug' or a 'crazy', 
but attempted to put faith in the democratic process itself. The U.S. foreign policy gains nothing by disrespecting large masses of foreign voters by calling their elected representatives 'thugs' or 'criminals', often reversing itself if and whenever convenient. Foreign policy must be about principles and processes, not based on disrespect for those who would venture to use them.

5. Internal resources. U.S. has erred often on the side of judging foreign individuals, parties and groups. Yet, all cultures and political experiences are abundantly available, more than anywhere else, in the U.S.A. No other country has absorbed so many emigrants, refugees, experts, politicians and asylum-seekers from so many countries. These are the most enviable resources which can caution, guide and guard against provinciality, naïveté, simplification and the 'gung-ho' of foreign policy conceived by a small and unrepresentative sample of bureaucratically cloned 'experts'. World resources should be better utilized in foreign policy formation and deliberations.

6. Embargoes and sanctions. These old, pre-global tactics of the ancient regime still continue to be overused and over-relied upon, especially in the U.S. foreign policy. Yet, in the new global framework, it is clear that sanctions achieve very little, isolate and thus strengthen the dictators, weaken democracy and punish the innocent population. These tactics, although admittedly quite simple to administer and sustain, should not be used because of their ineffectiveness and dangerous side-effects.

The above list may read like a set of self-evident 'no-nos' in any foreign policy of the global era. Yet, especially the U.S. has remarkably and inexplicably continued with relying on all or some of these old habits.

Modern foreign policy in the post-1989 world cannot be about a fixed strategy or vision, as it was during the cold war. What we perceive as turmoil, or even chaos, is in fact due to proliferation of forms, versions and embodiments of democracy, free markets and socio-political structures. Although the point of reference is global, its true and unimposed embodiment must be necessarily local. No democracy, no economy and no culture will or should be the same as American.

We cannot strengthen our democratic point of reference by condoning its dilution at home and abroad. We cannot stand on the side of shelling a parliament building if we ourselves would have cringed at the thought of such an action at home. At the same time, we cannot remain intolerant of an economic system which does not precisely resemble our own version of capitalism. Urging others to go fast when we ourselves prefer to take many years to introduce even minor adjustments is not quite moral.

Modern foreign policy must be more about the process, less about the outcomes. Concentrating on the outcomes only, while ignoring the internal processes and conditions elsewhere, has inevitably led to the loss of desirable outcomes. Modern foreign policy must be based on principles, not on personalities; it must respect the local voters and dismiss the journalistic labelling; it should not fixate a 'vision', but create a set of reference criteria and principles which would be tolerant of (and in fact celebrate) the many forms and 'deviations'.

To be intolerant with respect to principles could be a virtue. To be intolerant with respect to alternative forms, ways and embodiments is surely a vice.

In a global economy, the best foreign policy for the U.S. is the best domestic policy. What we do at home has the most powerful ordering effects on what is happening in the world. The so-called 'American way of life' of the post-war years was (and continues to be) a more powerful message than all the military might and celebrated policies of containment.

Not every country has such an enviable and powerful prerequisite to become the world leader by virtue of its own domestic policy. The way we manage our society, the way we live and the way we uphold our own principles travel faster and affect more deeply than the way we select leaders, deploy forces or shuttle diplomatic bodies. The world has changed and we have to acknowledge our strength and our implied role.

The modern world pays less attention to our armed forces, to our foreign doctrines and to our 'exports' on foreign policy. The world is far more fascinated by our open democratic discussions, our courageous dismantling of corporate hierarchies, our empowerment of employees and our continued cultural self-confidence. The world scrutinizes our efforts in the areas of crime, drug use and health care. No secretary of state can ever 'shuttle' enough to achieve even a comparable impact.

By standing for ourselves we would become able to stand for all the others. We would become free 
of double standards and the difference between words and action. It is our action which sends the message, not our words. We have to acknowledge the 'boundaryless' world as we were able to acknowledge the 'boundaryless' corporation. The 'boundaryless' world does not imply the end of nationalism, but the penetrability of boundaries for ideas, knowledge and examples. Nationalism would lose its threatening isolationistic habits and become what it truly should be: the local embodiment of global strivings. In such a world, the point of reference is vital and the U.S. should recognize this new role.

Such recognition cannot be created in a 'war room', it is not constructed by bureaucrats, but it should be implied by the actions of others. The actions of others indicate that they want to learn from the U.S. but not be taught by the U.S. It is not our role to teach but to provide the wealth of fundamental experiences to be learned.

The old fashioned distinction between foreign and domestic policies, although still potent and inevitable in many countries, is fast becoming an artefact in the U.S.A. Whether we acknowledge it or not, what we do at home is our foreign policy. It is better to know it than not. In the global world of instantaneous information, we remain in the floodlight, upon the hill, our actions, rather than our words, being forever scrutinized.

Milan ZELENY

Graduate School of Business Fordham University at Lincoln Center New York, NY 10023

U.S.A. 